\title{
Quevedo e a multiplicidade de significados nos Sueños (séc. XVII) nas traduções para o português, francês e inglês
}

\section{Quevedo and the multiplicity of meanings in Sueños (17th century) in translations into Portuguese, French and English.}

\author{
Andréa Cesco \\ Gilles Jean Abes
}

Resumo: Uma das marcas estilísticas de Quevedo em suas narrativas satíricas do século XVII são os jogos de palavras, irônica e humoristicamente provocativos, fundados na multiplicidade de significados de uma palavra (polissemia), o que provoca, de maneira mais ou menos explícita, o riso do leitor. Assim, nesse artigo são analisados comparativamente os recursos aplicados para as polissemias em três traduções dos Sueños, uma para o português do Brasil, realizada por Liliana Raquel Chwat (2006), uma para o inglês, com autoria de Wallace Woolsey (1976), e, finalmente, uma para o francês, elaborada por Annick Louis e Bernard Tissier (2003). Pautamos a nossa análise crítica nas reflexões de Paulo Henriques Britto, Mário Laranjeira ou ainda, Antoine Berman. Constatamos que a tradução desses trocadilhos representa um verdadeiro desafio para os tradutores que ora omitem, ora recriam esses traços de humor com novos jogos de palavras.

\footnotetext{
" Professor adjunto da Universidade Federal de Santa Catarina (UFSC), Departamento de Língua e Literatura Estrangeiras, professora da Pós-graduação em Estudos da Tradução (PGET/UFSC) E-mail: andrea.cesco@gmail.com

Professor adjunto da Universidade Federal de Santa Catarina (UFSC), Departamento de Língua e Literatura Estrangeiras (DLLE) e professor do programa de Pós-Graduação em Estudos da tradução (PGET/UFSC). E-mail: gilleufsc@gmail.com
} 
Palavras-chave: Crítica da Tradução. Polissemia. Sueños y Discursos. Quevedo y Villegas.

Abstract: One of the stylistic marks of Quevedo in his seventeenth-century satirical narrative is word game, it is ironic and humoristically provocative, based on the multiplicity of meanings of a word (polysemy), which provokes, in a more or less explicitly way, the laughter of the reader. Thus, in this article, the resources applied to the polissemias are analyzed comparatively in three translations of Sueños, one for the Brazilian Portuguese, by Liliana Raquel Chwat (2006), one for the English, with the authorship of Wallace Woolsey (1976), and, finally, one for the French, formulated by Annick Louis and Bernard Tissier (2003). We have based our critical analysis on the reflections of Paulo Henriques Britto, Mário Laranjeira, or yet, Antoine Berman. We have found that the translation of these word games represent a real challenge for the translators who either omit them, or recreate these moods with new word games.

Keywords: Translation Criticism. Polysemy. Sueños y Discursos. Quevedo y Villegas.

\section{Introdução}

Pretendemos, neste trabalho, analisar criticamente três traduções dos Sueños de Quevedo y Villegas: para o português do Brasil, de Liliana Raquel Chwat (Os sonhos, publicada pela Escala em 2006); para o inglês, de Wallace Woolsey (Dreams, publicada pela editora norte-americana Barrons Educational Series em 1976); e para o francês, de Annick Louis e Bernard Tissier (Songes et discours, pela editora parisiense José Corti em 2003). O texto de partida já que existem vários manuscritos dessa obra de Quevedo - é a edição consagrada de James 0. Crosby, Sueños y discursos, publicada pela editora madrilenha Castalia em 1993; porém, quando necessário, outras edições também são mencionadas.

Nosso objetivo é observar como esses tradutores recriaram os trocadilhos constituídos com palavras ambíguas. Mais especificamente, focamos o conceito de polissemia pela sua grande frequência na obra Sueños, pois essas marcas estilísticas representam um verdadeiro desafio para o tradutor, já que exigem, por um lado, um conhecimento lexical e cultural de 
uma época longínqua e, por outro, todo um trabalho de recriação para tentar reproduzir jogos de palavras do mesmo tipo em uma língua distinta. Para isso, pautaremos a nossa análise crítica nas reflexões de Paulo Henriques Britto (2012), Mário Laranjeira (2003) ou, ainda, Antoine Berman (2013).

\section{A polissemia em Quevedo}

O livro Sueños y Discursos é formado por cinco narrativas curtas, inspiradas no escritor grego satírico Luciano de Samósata, que se passam em um cenário ultratumba e que examinam de forma astuciosa os costumes, os personagens populares e as profissões da época. Nesse livro, Quevedo usa com frequência a polissemia como recurso humorístico e, ainda que no princípio nos deixemos levar pelo significado mais inocente e esperado, em seguida salta à vista o equívoco e a sua consequente nota de humor. O satírico costuma esclarecer o equívoco numa explicação imediata, mas às vezes é o leitor quem deve decifrar a dupla significação, desvelando a intenção humorística ou irônica.

No Diccionario de términos filológicos (1968), de Fernando Lázaro Carreter, encontramos a seguinte definição de polissemia: "Fenómeno consistente en la reunión de varios significados en una palabra" (1968: 243). Pottier Navarro (1991) diz que esse termo foi introduzido por Michel Bréal, em 1897, para designar, como indica sua etimologia, o fenômeno da multiplicidade de significações de uma palavra, "se trata, pues, de los diferentes valores que puede adoptar una palabra en una lengua natural ( $L N)$ determinada" (1991: 07).

A diáfora é uma das mais importantes formas de polissemia, consistindo no emprego de um termo com dois significados diferentes, um deles pertinente e outro absurdo, o que implica rupturas cômicas. Quevedo coloca uma palavra com dois sentidos distintos num contexto, e ele mesmo o resolve levando-o até o significado que normalmente não se esperava. Desta forma 
consegue jogos de palavras cheios de humor, sendo, em algumas ocasiões, relativamente acessíveis, e, em outras, exigindo certa reflexão por parte do leitor.

O desafio de traduzir esse humor reside na dificuldade de se recriar uma correspondência formal e/ou funcional para trocadilhos de um tempo distante, em outra língua, de modo a fazer rir um leitor atual.

\title{
3. Análise dos trocadilhos
}

No prólogo da narrativa "Alguacil endemoniado", o narrador se refere burlescamente ao leitor como pio, devoto, dotado de religiosidade e compaixão, e o faz para ridicularizar não só essa devoção como também os prólogos tradicionais que procuram adular o leitor. Logo depois, faz uma piada com Enéias e natural del pollo, que está baseada, segundo Ignacio Arellano (1999: 137), na diáfora de pío, que remete, ao mesmo tempo, a "piedoso", à onomatopeia do piar do pinto e ao epíteto de pius que costuma acompanhar o nome Aeneas em latim, formando o sintagma Pius Aeneas.

\begin{abstract}
AL PíO LECTOR. Y si fueres cruel y no pío, perdona, que este epíteto natural del pollo has heredado de Eneas, y en agradecimiento de que te hago de cortesía el no llamarte benigno lector, advierte que hay tres géneros de hombres en el mundo $[\ldots]^{1}$ (QUEVEDO Y VILLEGAS 1993: 156).
\end{abstract}

Nesse trecho, encontramos pequenas diferenças nas edições. Crosby (1993) e Arellano (1999) mantêm a locução natural del pollo, enquanto Maldonado (1982) coloca del pollo em itálico. Já Felicidad Buendía (1981) omite natural del pollo, mas indica, em uma nota de rodapé, que no original havia essa locução que ela achou melhor omitir.

Outra palavra que apresenta relação com pío, no trecho destacado do

\footnotetext{
${ }^{1}$ Nos trechos mencionados, os grifos em negrito são nossos, visando enfatizar as polissemias analisadas nas traduções.
}

TradTerm, São Paulo, v. 30, Novembro/2017, p. 8-24 
prólogo, é benigno, pois, segundo o dicionário Academia Autoridades (1726: p. 594,2), pío "afable, humano, piadoso e de ánimo compasivo, blando y amoroso." No entanto, temos novamente um jogo com a palavra benigno. Segundo Arellano (1999: 138), esse adjetivo era bastante usual naquela época, e o satírico pode estar jogando tanto com a semelhança de sons com venino como com benino (a forma mais antiga de benigno). 0 primeiro, venino, pode ser o adjetivo "venenoso", o substantivo "veneno" ou, ainda, segundo o Diccionario de la Real Academia Española (RAE) digital, "grano maligno o divieso". Crosby acrescenta ainda, em nota de rodapé, que "llamar a uno benigno era decir que tenía sarna pero en forma benigna; y emplear esta imagen de manera burlesca en el contexto de una dedicatoria es una parodia de ciertos libros de erudición en latín, que rezan, 'Benigni lectori:..."' (1993: 156). Quevedo também usa esse mesmo adjetivo na dedicatória da narrativa "El mundo por de dentro": "Al lector, como Dios me lo depare: cándido o purpúreo, pío o cruel, o benigno o sin sarna" (1993: 274).

Chwat em sua tradução mantém "pio" e "benigno", mas omite natural del pollo que, como vimos no comentário de Arellano, remete à onomatopeia do som emitido pelo pinto e ao epíteto pius que forma o sintagma Pius Aeneas.

AO PIO LEITOR. Se fores cruel e não pio, perdoa, pois este epíteto herdaste de Enéas. Em agradecimento que faço à cortesia, por não te chamar de benigno leitor, perceba que há três tipos de homens no mundo: [...] (QUEVEDO Y VILLEGAS 2006: 38).

Em francês, observam-se duas deformações, uma consequência da outra: a de clarificação que gera a de alongamento, para usar aqui a terminologia do Antoine Berman (2013). Berman, em A tradução e a Letra ou o Albergue do Longínquo, ${ }^{2}$ afirma que a clarificação, "é inerente à tradução, na medida em que todo ato de traduzir é explicitante"; e, num sentido

\footnotetext{
${ }^{2}$ Nessa obra Berman defende a ideia de que, para termos acesso à verdade da tradução, sua verdade ética, é preciso que haja destruição das teorias reinantes (sistemática da deformação) e uma análise das tendências deformadoras (analítica da tradução) que operam em toda tradução, abrindo, assim, um espaço positivo para o ato de traduzir. Partindo desse princípio, o autor seleciona treze tendências, afirmando que elas formam um todo - letra do texto - e discute como elas se manifestam no texto traduzido.
} 
negativo, "a explicação visa a tornar 'claro' o que não é e não quer ser no original. A passagem da polissemia à monossemia é um modo de clarificação" (2013: 70-71).

De fato, conforme pode ser constatado na versão francesa, reproduzida a seguir, os tradutores explicitam o jogo de palavras entre benigno ou benino com venino, do espanhol, através do emprego da expressão adjectif à venin. Além disso, na busca legítima por uma correspondência, como diria Paulo Henriques Britto (2012: 19), ou seja, por uma reprodução, por exemplo, do tom deste trecho em língua francesa, os tradutores criaram um jogo de palavras, próximo da paronomásia, com os termos pieux, pitié e piété. Dada a complexidade da tradução do excerto em questão, o resultado final não recriou a mesma imagem elaborada no texto de Quevedo. Mesmo assim, podemos destacar um trocadilho interessante no emprego do adjetivo pie junto a oeuvre. Normalmente, a expressão seria oeuvre pie, que significa "ação inspirada pela piedade". No entanto, ao inverter as palavras, ao ler pie e oeuvre nessa ordem, a sequência desses fonemas também forma a palavra pieuvre. O termo significa "polvo" (molusco) e também uma pessoa tenaz, insaciável, que não solta sua presa, além de uma concubina que causa a ruína de seu protetor.

Au pieux lecteur. Pardonne-moi cette épithète - si être sans pitié ni piété tu n'as que répugnance pour la moindre pie oeuvre - en songeant qu'elle est un héritage d'Énée. Et en remerciement de la courtoisie dont je fais preuve en ne t'appelant point bénin, adjectif à venin, prête attention au fait qu'il y a trois sortes d'individus au monde: [...] (QUEVEDO Y VILLEGAS, 2003: 54).

Talvez os tradutores franceses pudessem aproveitar ainda mais a polissemia do vocábulo pie, que é empregado como substantivo feminino para vários pássaros de cor preta e branca, referindo-se originalmente ao pássaro chamado pie bavarde (a pega-rabuda ou pega-rabilonga). Trata-se da espécie pica pica, da família dos Corvidae (corvos) que vive na América do norte, Europa, Ásia e norte da África. O termo bavarde significa literalmente "tagarela", pois trata-se de um pássaro muito barulhento. Tem a reputação inclusive de roubar objetos brilhantes. Daí a expressão em francês bavard 
comme une pie (tagarela como uma pega-rabuda). Tem, assim, acepções ligadas à tagarelice ou ao roubo e, como adjetivo, como vimos, tem relação com a piedade. Dessa forma, ao não traduzir semanticamente o trecho, já que alteraria o tipo de ave, reproduzir-se-ia essa correspondência funcional ligada ao duplo sentido de pío do espanhol, recriando o trocadilho humorístico. No que tange ao termo benigno, uma solução seria usar o vocábulo véniel, sinônimo de bénin em francês, que tem, por um lado, uma relação com a isotopia religião e, por outro, é mais próximo de venin (veneno) pela grafia. Poderia ficar assim:

$\mathrm{Au}$ lecteur pie. Et si tu es cruel et non pie, pardonne-moi cette épithète, naturel de la pie, que tu as héritée d’Énée, et en remerciement de la courtoisie dont je fais preuve en ne t'appelant point véniel, prête attention au fait qu'il y a trois sortes d'individus au monde: [...] (Trad. nossa)

É curioso notar, em relação à solução feita com a escolha dessa ave (la pie), que tem a reputação de roubar objetos que brilham e de ser tagarela, que Enéas, do latim Aeneas, significa “do cobre”, que é justamente um metal da mesma família que a prata e o ouro - portanto, que brilha - e é também atribuído a instrumentos musicais. O adjetivo cuivré, em francês, significa, aliás, l'éclat sonore du cuivre [o estrondo/resplendor sonoro do cobre]. A palavra éclat pode significar tanto "estrondo", "barulho" quanto "resplendor", "brilho", e já foi empregada para se referir ao som dos pássaros, por exemplo, na obra La mort dans l'âme (Com a morte na alma), de Jean-Paul Sartre (1949: 43):

Dans le feuillage des peupliers, obéissant à un signal invisible, une multitude d'oiseaux se mirent à chanter à plein gosier, ce fut une petite rafale cuivrée d'une violence extraordinaire [...].

Nas folhagens dos álamos, uma multidão de pássaros pôs-se a cantar a plenos pulmões, foi uma pequena rajada cobreada de extraordinária violência [...] (Trad. nossa)

Dessa forma, cria-se um novo jogo de significações para o sintagma Pius Aeneas. 
0 tradutor para o inglês parece ter tido mais dificuldade para recriar o trocadilho, certamente por causa da ausência de polissemia da palavra pious em inglês, ao menos no que diz respeito a essa acepção da ave. Daí a necessidade de explicar o jogo de palavras com baby chick. Woolsey tenta reproduzir a provocação que Quevedo faz ao leitor, de forma explícita, ao optar pela expressão king reader entre aspas, talvez para marcar uma ironia. Nessas situações, em que as diferenças dos idiomas costumam elevar barreiras, a recriação é a única solução, uma recriação que não tem como repetir a semântica exata do trocadilho, mas que pode, por outros jogos, reencontrar a letra do texto.

To the pious reader.

And if it turns out that you are cruel and not pious, please forgive me. From Aeneas, form whom you are descended, you have inherited this epithet that comes natural to the baby chick. And in appreciation of the fact that I do you the favor of not calling you "king reader", please note that there are three classes of men in the word. [...] (QUEVEDO Y VILLEGAS, 1976: 23).

Acreditamos que a nota de rodapé, para certas passagens como esta, é também um recurso admissível e, segundo Álvaro L. Hattnher, "(quando não obrigatório) quando se trata da tradução de uma obra literária que situe um contexto cultural totalmente diverso daquele expresso pela língua de chegada” (1985: 89). A nota serve, muitas vezes, para ampliar a visão do todo cultural composto pela obra. Caberá ao tradutor, em seu projeto de tradução, prever o uso dessas notas. Para isso, é claro, o tradutor deverá definir o público alvo e levar em conta (ou seguir) o projeto editorial.

$\mathrm{Na}$ passagem seguinte, da narrativa "El mundo por de dentro", o jogo está no vocábulo causa, que tanto pode significar "razão", "motivo", “origem” como também “ação judicial”, “demanda”, “pleito”.

-Ríete de eso -dijo-. ¿Has visto tú algún alguacil sin escribano algún día? No por cierto, que como ellos salen a buscar de comer, porque (aunque topen un inocente) no vaya a la cárcel sin causa, llevan al escribano que se la haga; y así, aunque ellos no dan causa para que los prendan, hácesela el escribano y están presos con causa (QUEVEDO Y VILLEGAS, 1993: 294). 
Sabe-se que os escrivães naquela época eram tachados de falsificadores e subornados, juntamente com os meirinhos, tidos como seus comparsas. Eram acusados de alterar os depoimentos das testemunhas (CESCO: 2007). Chwat provavelmente não percebeu a importância do duplo sentido nesta passagem e assim traduziu:

- Podes rir - disse ele - Você já viu seu alguazil alguma vez sem escrivão? Certamente que não, pois como eles saem para procurar o que comer, mesmo que encontrem um inocente, para que não vá para a cadeia sem motivo, levam um escrivão para que o encontre; mesmo que não deem motivo para que os prendam, o encontra o escrivão, e assim vão presos com motivo (QUEVEDO Y VILLEGAS, 2006: 90).

Outra vez podemos mencionar uma das deformações de que trata Berman, já citada anteriormente, em que "a passagem da polissemia à monossemia é um modo de clarificação" (2013: 70-71).

Louis e Tissier, como Quevedo, jogam com os significados de "causa" e com suas expressões idiomáticas: sans cause (sem motivo), en tout état de cause (de qualquer maneira), cause en état (em jargão jurídico, causa pronta para ser julgada), mise en cause (acusado).

\footnotetext{
- Raille à ta guise! As-tu jamais vu alguazil sans greffier? Non assurément, car les alguazils, lorqu'ils partent à la chasse, et afin que leur proie - fût-elle innocente - ne soit pas incarcérée sans cause, de sorte qu'en tout état de cause, la cause est en état et la victime est mise en cause (QUEVEDO Y VILLEGAS, 2003: 141).
}

Na passagem seguinte, da narrativa "Sueño de la Muerte", aparecerá o sacamuelas (tira-dentes), outro ofício maldito para a literatura satírica. Os tira-dentes, e muitas vezes os barbeiros (praticantes de sangrias, entre outros, que exerciam também o papel de tira-dentes), gozam de uma posição de privilégio na história do sofrimento humano. Como comenta Quevedo (1993: 325), este é "el oficio más maldito del mundo, pues no sirven sino de despoblar bocas y adelantar la vejez". No século XVII, sem usar anestesia e com boticões e alicates, eles podiam, além de extrair dentes sadios ou doentes, desconjuntar a mandíbula e deslocar o maxilar. 
En tanto vi venir unos demonios con unas cadenas de muelas y dientes, haciendo bragueros, y en esto conocí que eran sacamuelas, el oficio más malo de todo el mundo, pues no sirven sino de despoblar bocas y adelantar la vejez. Éstos comen con las muelas ajenas, y no ven diente que no quieran ver antes en su collar que en las quijadas; desconfían a las gentes de santa Polonia, levantan testimonio a las encías y desempiedran las bocas. No he tenido peor rato que tuve en ver andar sus gatillos tras los dientes ajenos como si fueran ratones, y pedir dineros por sacar una muela como si la pusieran (QUEVEDO Y VILLEGAS, 1993: 325).

Arellano comenta que os tira-dentes "solían llevar los dientes que iban a poner postizos colgados a modo de collar y eran también fabricantes de bragueros para remedios de herniados" (QUEVEDO Y VILLEGAS, 1999: 322). 0 narrador declara que as pessoas até passam a desconfiar de Santa Apolônia, a padroeira dos dentistas; ${ }^{3}$ e, humanizando as gengivas, afirma que eles mentem para elas, dando falso testemunho, para arrancarem os dentes.

No final dessa passagem, Quevedo joga com os significados das palavras rato, gatillo e ratón. Rato e ratón, segundo o dicionário da Real Academia Española, digital, se referem ao mamífero roedor, porém não comentam que está em desuso, porque rato, em espanhol, é usado atualmente para se referir ao curto espaço de tempo; instante, ocasião. No WordReference há uma entrada para um fórum de discussão que questiona o significado de rato, de ser também "el macho de la rata". O dicionário Academia Autoridades de 1737 já apontava esta palavra como antiga: "Lo mismo que Ratón. En este sentido se solía usar en lo antiguo, y hoy se usa en algunas partes" (1737: $497,1)$. Portanto, seu uso por Quevedo é totalmente humorístico, com o intuito de jogar com as palavras. Gatillo, em espanhol, é o instrumento de ferro para arrancar dentes; mas faz alusão ao "gatinho" (felídeo). Ou seja, os gatillos (boticões/gatos) estão atrás dos dentes alheios como se estes fossem ratos.

Na tradução de Chwat, a frase a seguir é cortada: "desconfían a las gentes de santa Polonia, levantan testimonio a las encías y desempiedran las bocas". E assim fica na sequência: "Não houve pior momento que quando os vi

\footnotetext{
${ }^{3}$ Diz a tradição que, antes de ser assassinada, no seu martírio, quebraram-lhe os maxilares e arrancaram os seus dentes com uma espécie de alicate da época.
}

TradTerm, São Paulo, v. 30, Novembro/2017, p. 8-24

www.usp.br/tradterm 
ir atrás dos dentes alheios, e pedindo dinheiro para tirá-los como se os estivessem colocando" (QUEVEDO Y VILLEGAS, 2006: 100).

Tanto Woolsey quanto Louis e Tissier lançam uma nota de rodapé explicativa para Santa Apolônia. A solução de Woolsey é simples e inspirada pela imagem que Quevedo evoca (gatos perseguindo ratos): "I have never had a worse moment than I had as I saw their cat-like pincers going after other people's teeth as if they were mice, and asking money for taking out a tooth, just as if they were putting one in" (QUEVEDO Y VILLEGAS, 1976: 131). Woolsey desdobra os possíveis sentidos de gatillo, descrevendo as pinças do boticão como se fossem as garras de um gato. 0 uso da símile (alicates como gatos) neste ponto é autenticado pelo fato de que o próprio Quevedo a utiliza mais adiante (dentes como ratos). A única diferença reside no fato de Quevedo derivar sua símile de jogos de palavras, ao passo que, em inglês, a ausência de base sonora faz com que soe como uma aproximação autêntica do escritor. Isso não é necessariamente ruim, já que a imagem dos gatos perseguindo ratos é suficientemente coerente, mas o trecho soa ligeiramente menos engenhoso, pois os jogos de palavras "naturalizam" as ideias. A tradução francesa, mencionada a seguir, joga com daviers (boticão), explorando o duplo sentido de souris que significa "camundongo", mas também, num sentido mais antigo ou poético, é sinônimo de "sorriso" (souris ou sourire em francês). A primeira, daviers, pode significar tanto a tenaz para arrancar dentes como o instrumento usado por tanoeiros, chamado "gato" (ALVIM CORRÊAA, 1961: 154), cuja função é, segundo o dicionário Aulete Digital, "arquear vasilhas e endireitar aduelas de pipa".

Je n'ai connu pire moment que celui où il me fallut les voir, armés de daviers, qui couraient sus aux dents d'autrui comme après des souris, et qui réclamaient des deniers pour arracher une molaire comme s'il s'agissait de l'enraciner (QUEVEDO Y VILLEGAS 2003: 155).

O humor surge justamente da ideia do dentista correndo atrás de sorrisos, como se fossem ratos.

Nessa outra passagem de "Sueño de la Muerte", el Otro, explicado por 
Crosby, em nota de rodapé, como "personaje tradicional en el refranero y en algunos cuentos", também marcará presença para reclamar:

\begin{abstract}
Volvíme [narrador] y era un muerto muy lacio y afligido, muy blanco y vestido de blanco, y dijo: [...] yo soy el Otro, y me conocerás, pues no hay cosa que no lo diga el Otro. $Y$ luego en no sabiendo cómo dar razón de sí, dicen: "Como dijo el Otro". [...] Y quiero por amor de Dios que vayas al otro mundo y digas cómo has visto al Otro en blanco, y que no tiene nada escrito, y que no dice nada ni lo ha de decir ni lo ha dicho, [...] - ¿Aún aquí estáis, y no queréis dejar hablar a nadie? -dijo un muerto (hablando armado de punto en blanco muy colérico) (QUEVEDO Y VILLEGAS, 1993: 371-2).
\end{abstract}

O narrador descreve-o como flácido, desconsolado, e "muito branco", com o sentido, aqui, de pálido, descorado (morto); e estava vestido de "branco", da cor da neve. Depois, pede ao narrador que diga ao outro mundo como viu o Outro em branco, ou seja, nada escrito, sem conteúdo, vazio; ou ainda, sem haver estudado nada. Quando outro morto fala, estará armado de punto en blanco, que segundo o dicionário Academia Autoridades (1726: $615,2)$, é "cubierto de armas blancas todo el cuerpo, desde los pies hasta la cabeza."

Woolsey é literal, e o jogo de palavras desaparece; Louis e Tissier conseguem estabelecer o jogo com o vocábulo blanc, mas na última frase a expressão armado de punto en blanco é substituída por outra que prioriza o significado, armé de pied en cap (armado da cabeça aos pés). Chwat também reproduz o jogo polissêmico com "branco", mas elimina a expressão que fecha esse trecho: armado de punto en blanco. Uma alternativa seria dizer que ele estava "coberto com armas brancas da cabeça aos pés".

Virei-me e vi que era um morto muito escorrido e aflito, muito branco e vestido de branco, que disse: [...] eu sou o Outro, e me conhecerás, pois não há quem não diga "o Outro" e, depois, não sabendo como dar conta de si, diga: "Como disse o Outro". [...] Quero, pelo amor de Deus, que lá no outro mundo digas que viste o Outro, em branco, que não tem nada escrito, que não diz nada, nem disse nem dirá; [...] - Ainda estás aqui e não deixas ninguém falar? - disse um morto muito colérico (QUEVEDO Y VILLEGAS 2006: 118). 


\section{Considerações finais}

Como vimos, traduzir a prosa quevediana não é tarefa simples e exige não somente conhecimento do idioma - inclusive do espanhol do século XVII como uma grande inventividade da parte do tradutor. Mais especificamente nos trechos analisados logo acima, foi possível observar as tentativas de regaste da polissemia, espaço de jogo da sátira, ou seu total apagamento, o que gerou uma perda considerável. No entanto, o que essa perda significa? Qual é seu valor? O que está em jogo na busca por essa polissemia?

No que tange à recriação destes termos polissêmicos, acreditamos que as reflexões de Mário Laranjeira acerca do signo duplo, em seu livro Poética da tradução: do sentido à significância (2003), podem ser bastante relevantes para melhor entender a importância da polissemia. Não se trata aqui "apenas" da perda de um duplo sentido, ou seja, do apagamento de uma das acepções de uma palavra - como pudemos observar nos trechos analisados - que não teria maiores consequências para o texto de chegada. Ao contrário, ao associar os jogos de palavras de Quevedo ao conceito de signo duplo, destacamos um traço poético da sua escrita. De fato, muito mais do que um trocadilho, o signo duplo, ou ponto nodal, funciona como um hipograma, uma palavra-tema, "cujo interpretante poderá situar-se em nível intertextual ou simplesmente no continuum lingüístico-cultural do grupo social" (LARANJEIRA, 2003: 105). Assim sendo, além da onipresença destes jogos de palavras nos Sueños de Quevedo, estes fazem parte de um modo de dizer da sátira quevediana, que toma sentido apenas nas relações intertextuais e com conhecimentos de questões culturais da época do autor seiscentista. Para exemplificar, citemos o caso da palavra pío (pio), visto anteriormente, que, muito mais do que ter uma simples duplicidade de sentido, dá força à sátira, animando-a em sua ligação com as relações que Quevedo mantinha com seus leitores e críticos. Pío é assim um ponto nodal, já que apresenta um desafio de tradução, mas também é o ponto de articulação em torno do qual o trocadilho satírico toma corpo. Embora não se trate de poesia, percebemos 
que a reflexão que Laranjeira aplicou, por exemplo, à análise da tradução francesa do "Poema-orelha" de Drummond ajuda-nos a melhor circunscrever a função do signo duplo para a sátira. De fato, o título do poema do poeta mineiro é formado pelo signo duplo "orelha", que significa tanto uma parte do aparelho auditivo e quanto a dobra da capa do livro, mas essa ambiguidade sobre a qual o poema se sustenta não existe em francês. 0 elemento gerador de poeticidade, como diz Laranjeira (2003), está justamente na obliquidade da palavra orelha.

E como proceder então para reproduzir o signo duplo? À guisa de exemplo tomemos novamente um poema citado e traduzido por Laranjeira, "Mea culpa", de Jacques Prévert, reproduzido abaixo:

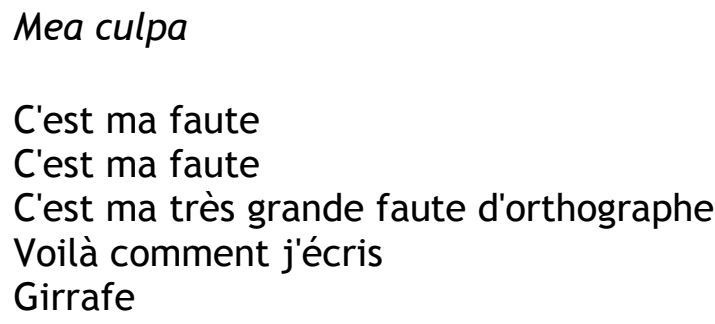

Nesse poema, a poeticidade repousa novamente no título, que funciona como um interpretante textual que é um fragmento do texto que serve de chave de interpretação para o poema como um todo. Nesse caso, o signo duplo está na palavra faute (culpa, erro) que na frase "C'est ma faute" (É minha culpa) joga com o início e a gravidade de uma confissão e muda abruptamente para a isotopia escolar. $\mathrm{Na}$ tradução de Laranjeira (LARANJEIRA, 2003: 105-107), leva-se em conta a isotopia da liturgia e mantém-se o signo duplo, sem o qual a poeticidade se perderia.

Mea culpa

É minha culpa

É minha culpa

Minha máxima culpa em ortografia

Vejam como escrevi

Bassia

TradTerm, São Paulo, v. 30, Novembro/2017, p. 8-24

www.usp.br/tradterm 
Conforme a análise de Laranjeira, Silviano Santiago acaba suprimindo, em sua tradução, o efeito mais significativo do poema ao traduzir apenas um dos sentidos da palavra faute:

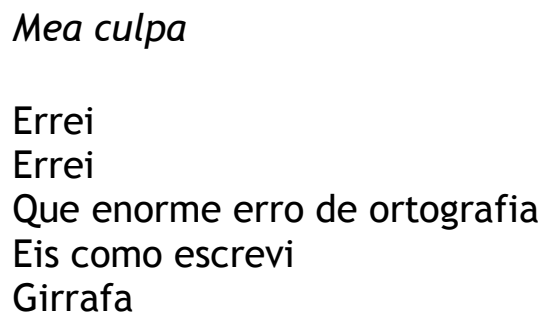

Laranjeira entendeu que o título era justamente a chave de leitura do poema e o signo duplo seu espaço de jogo. Para manter a poeticidade, precisou resgatar a ambiguidade da confissão - Mea culpa - que brinca com uma suposta gravidade do erro ortográfico. De fato, em francês, não há diferença de pronúncia entre as grafias "r" e "rr". É, portanto, um engano bastante lógico e aceitável, recriado pelo tradutor com a mudança de vocábulo: "bassia" para "bacia". Somente assim, Laranjeira conseguiu reproduzir o efeito do poema, não perdendo de vista a função do signo duplo.

Esses exemplos do estudo de Laranjeira dão destaque à importância de se recriar esta significância do texto quevediano: a polissemia como signo duplo. Pois é disso que se trata: de significância, e não apenas de sentido. Sem a reinvenção desse elemento, o riso de Quevedo - enquanto forma de questionar o mundo, tal qual o entendimento de Bakhtin (2013: 57) - deixaria de ser.

\section{Referências bibliográficas}

Academia Autoridades, in Real Academia Española. Diccionario de la lengua castellana, en que se explica el verdadero sentido de las voces, su naturaleza y calidad, con las phrases o modos de hablar, los proverbios o refranes, y otras cosas convenientes al uso de la lengua [...]. Compuesto por la Real Academia Española. Tomo primero. Que 
contiene las letras A.B. Madrid. Imprenta de Francisco del Hierro. 1726. Reproducido a partir del ejemplar de la Biblioteca de la Real Academia Española.

Academia Autoridades, in Real Academia Española. Diccionario de la lengua castellana, en que se explica el verdadero sentido de las voces, su naturaleza y calidad, con las phrases o modos de hablar, los proverbios o refranes, y otras cosas convenientes al uso de la lengua [...]. Compuesto por la Real Academia Española. Tomo quinto. Que contiene las letras O.P.Q.R. Madrid. Imprenta de la Real Academia Española, por los herederos de Francisco del Hierro. 1737. Reproducido a partir del ejemplar de la Biblioteca de la Real Academia Española.

ALVIM CORRÊA, Roberto (org.). Dicionário escolar francês-português, português-francês. 2a ed. Ministério da Educação e Cultura. Rio de Janeiro: Artes gráficas Gomes de Souza S. A., 1961.

BAKHTIN, Mikhail. A cultura popular na Idade Média e no Renascimento: 0 contexto de François Rabelais. Tradução de Yara Frateschi Vieira. São Paulo: Hucitec, 2013.

BERMAN, Antoine. A tradução e a Letra ou o Albergue do Longínquo. Tradução de Marie-Hélène C. Torres, Mauri Furlan e Andréia Guerini. $2^{\mathrm{a}}$ ed.

Tubarão: Copiart; Florianópolis: PGET/UFSC, 2013.

BRITTO, Paulo Henriques. A tradução literária. Rio de Janeiro: Civilização Brasileira, 2012.

CESCO, Andréa. "A sátira nos chamados agentes da lei, nos Sueños de Quevedo", in Anuario brasileño de estudios hispánicos, ISSN 0103-8893, $\mathrm{N}^{\circ} \quad 17, \quad 2007, \quad$ pp. 23-32. Disponível em https://dialnet.unirioja.es/ejemplar/385127

DICIONÁRIO AULETE DIGITAL. Lexicon Editora Digital. Verbete gato (8). Disponível em: <http://www.aulete.com.br>. Acesso em: 12 abril 2016.

HATTNHER, Álvaro L. Nota de pé de página: Alicerce Fundamental da Tradução. Tradução e Comunicação - Revista Brasileira de Tradutores. Faculdade Ibero-Americana de Letras e Ciências Humanas. Ed. Álamo. São Paulo, nº 6, 1985.

LARANJEIRA, Mário. Poética da tradução: do sentido à significância. São Paulo: Edusp, 2003.

LÁZARO, Carreter, Fernando. Diccionario de términos filológicos. $3^{\mathrm{a}}$ ed. Madrid: Gredos, 1968.

QUEVEDO Y VILLEGAS, Francisco de. Dreams. Tradução de Wallace Woolsey. 
Woodbury: Barron's Educational Series, 1976.

- (edição de Felicidad Buendía). Obras completas: Obras en Prosa.

V. 1. Madrid: Aguilar, 1981.

- (edição de Felipe C. R. Maldonado). Sueños y Discursos. Madrid: Castalia, 1982.

- (edição anotada de James O. Crosby). Sueños y Discursos. Madrid: Castalia, 1993.

. (edição anotada de Ignacio Arellano). Los sueños. $3^{\mathrm{a}}$ ed. Madrid: Cátedra, 1999.

- Songes et discours. Tradução de Annick Louis e Bernard Tissier. . Paris: José Corti, 2003.

Escala, 2006.

Os sonhos. Tradução de Liliana Raquel Chwat. São Paulo:

POTTIER NAVARRO, Huguette. La polisemia léxica en español: teoría y resolución. Versão espanhola de Segundo Álvarez Pérez. Madrid: Gredos, 1991.

WORDREFERENCE.COM. Language Forums. Rato (macho de la rata) $i$ ? Disponível em: https://forum.wordreference.com/threads/rato-machode-la-rata-\%C2\%BF.318568/ Acesso em: 12 abril 2016. 